\title{
RELIGIÓN Y ESPIRITUALIDAD, UNA MIRADA DEL ESTIGMA FRENTE AL VIH/SIDA: REVISIÓN LITERARIA
}

\author{
Leonardo Arévalo Mora ${ }^{1}$, Sandra Paola Ávila Mira ${ }^{2}$ \\ ${ }^{1}$ Médico Cirujano, Universidad Nacional de Colombia. Magíster (C) Salud Sexual y Reproductiva, \\ Universidad El Bosque. Médico Programa VIH/SIDA. EPS SURA. Bogotá D.C. Colombia. \\ ${ }^{2}$ Médica Epidemióloga, Universidad El Rosario. Magíster (C) Salud Sexual y Reproductiva, Universidad El Bosque. \\ Medico coordinador COPRECOS Colombia.
}

\begin{abstract}
Resumen
En el presente artículo se hace una revisión de la literatura acerca de la religión, la espiritualidad y su papel en la epidemia del Virus de Inmunodeficiencia Humana y del Síndrome de Inmunodeficiencia Adquirida (VIH/SIDA). Primero se determina el contexto general de la religión vs la espiritualidad a la luz de vivir con VIH. También se hará un abordaje de las limitaciones existentes en las principales religiones alrededor del mundo, con respecto al estigma de la enfermedad. Y finalmente, se describe cuales han sido las acciones beneficiosas por parte de las comunidades religiosas.
\end{abstract}

Palabras clave: Religión, espiritualidad, VIH, SIDA

\section{RELIGION AND SPIRITUALITY, A VIEW OF STIGMA AGAINST HIV/AIDS: LITERATURE REVIEW}

\begin{abstract}
This article is a review of the literature on religion, spirituality and its role in the HIV/AIDS epidemic. First determine the overall context of religion vs spirituality related to living with HIV, then investigates the constraints with the major religions around the world regarding the stigma of the disease and finally, describes the actions which have been beneficial by religious communities.
\end{abstract}

Key words: Religion, spirituality, HIV, AIDS

\section{RELIGIÃO E ESPIRITUALIDADE, UM OLHAR DO ESTIGMA DIANTE DO HIV/AIDS: REVISÃO LITERÁRIA}

\begin{abstract}
Abstrato
No presente artigo, faz-se umarevisão da literatura a respeito da religião, espiritualidade e seu papel na epidemia do vírus da imunodeficiência humana e da síndrome da imunodeficiência adquirida (HIV/AIDS). Primeiramente, determina-se o contexto geral de religião versus espiritualidade à luz daqueles que vivemcom HIV. Aborda-se também as limitações existentes nasprincipaisreligiõesao redor do mundo comrespeitoao estigma da doença. Finalmente, descrevem-se quaistêm sido as ações benéficas por parte das comunidades religiosas.
\end{abstract}

Palavras-chave: Religião, espiritualidade, HIV, AIDS

* Correo electrónico: leonardoarevalo@tutopia.com Correo electrónico: sandra.pao.1@hotmail.com 


\section{Introducción}

La historia de la enfermedad por el Virus de la Inmunodeficiencia Humana (VIH/SIDA), ha cursado por varias etapas en su comprensión y entendimiento, que inicia desde el conocimiento de su historia natural que se ha visto modificada por el manejo del esquema de tratamiento antirretroviral altamente efectivo (HA$\mathrm{ART}$ ), y que conlleva a que el paciente logre entender la patología como una enfermedad crónica en la cual se retrasa la progresión de la enfermedad (1), se estabiliza el estado inmunológico, se reconoce y aclara las vías de transmisión, y se llega a comprender que es una pandemia que no tiene credos, ni preferencias (2). Para el estudio del tema a abordar, se realizó una revisión de literatura publicada desde enero de 1985 a octubre de 2011, utilizando las bases de datos de medline, scielo, lilacs, google academic, y consultando las publicaciones que estuvieran relacionados con los términos: "religión", "espiritualidad", "VIH", "SIDA" en idioma español e inglés. Se priorizó sobre los artículos que abordaran el tema acerca del impacto de la relación planteada, de las posiciones adoptadas por cada religión, y de las intervenciones alrededor del mundo.

\section{Contexto general}

Es bien conocido que en lo relacionado a la infección por VIH se tiende a rechazar al paciente, por la falta de conocimiento o por ideas preconcebidas. En la sociedad, algunos expertos han llegado a citar este fenómeno como el VIH social $(3,4)$, que incluye a diferentes sectores entre los cuales están los relacionados con el credo y la religión, quienes pueden modificar o señalizar el significado de vivir con VIH/SIDA. En Colombia se ve reflejado en los datos presentados por la Encuesta Nacional de Demografía y Salud de 2010, en la cual el porcentaje de aceptación del paciente es tan solo del 15\% (5).

Dentro de este contexto tiene un papel muy importante el estigma, (proceso social que invalida y subvalora a quien sea dueño de una característica específica) (6), que debe ser intervenido en todos los ámbitos involucrados y no solo a partir del paciente. Algunos de ellos y los que más influencia tiene a nivel mundial son la religión y la espiritualidad; esta última entendida como la necesidad del ser humano de encontrar solución a diversos cuestionamientos acerca de la vida, su valor, su expresión y la correlación con lo sagrado, que es dado por la experiencia como funcional, dinámico, personal, y subjetivo $(7,8)$. La espiritualidad no está relacionada de manera directa con la religión y se encuentra establecida en todas las culturas; por su parte la religión, se define como la estructura de dogmas, experiencias, significados y atributos que facilitan la relación con un ser supremo, la manera como cada quien la vive y la forma de expresión de la fe (7).

En los últimos años se ha presentado un interés progresivo por establecer la relación entre la dimensión mental y física de los aspectos de religión y espiritualidad y su influencia en enfermedades crónicas. Así la religión y la espiritualidad, se constituyen en herramientas de gran importancia para los pacientes con $\mathrm{VIH}$, que las usan de manera frecuente para afrontar la enfermedad, los sentimientos de culpa, vergüenza y encontrar una renovación frente al sentido y propósito en la vida $(9,10,11)$. Este tipo de abordajes sirven como apoyo en la construcción del duelo y el afrontamiento de la muerte. La espiritualidad en particular, se convierte en un factor trascendental en la vida, ya que implica ir más allá del concepto de la religión tradicional, utilizado en el acompañamiento de la enfermedad, sin importar el credo y con el fin de llegar a un equilibrio entre la salud mental y física (12). A partir de la espiritualidad se contemplan los valores, el sentido de la vida y de todo lo que rodea al individuo.

Algunas investigaciones plantean que la religión y la espiritualidad pueden aminorar los comportamientos de riesgo y por lo tanto servir como una barrera frente a la infección por el VIH (13), además se ha demostrado en pacientes experimentados con diagnóstico de $\mathrm{VIH}$ que pueden presentar síntomas depresivos significativos (14). Estos síntomas fueron relacionados con un estado de salud deteriorado, con inadecuadas percepciones acerca de la enfermedad $(15,16)$, menor apoyo social, y menor bienestar espiritual $(17,18)$. En lo que concierne al modelo paciente-enfermedad, ya se ha expuesto que si hay altos niveles de depresión en el paciente, esto puede llevar a disminuir los recuentos celulares de linfocitos CD 4 (19,20), los cuales son la base del deterioro del sistema inmunológico y su disminución ocasiona una inmunosupresión con las correspondientes infecciones oportunistas que se pueden desarrollar.

Siegel ha encontrado en sus estudios que los pacientes que tienden a ser más religiosos reflejan mayor 
optimismo, mayor autoestima, mayor satisfacción con la vida, y menor ingesta de alcohol (21). De igual manera los individuos incorporan la espiritualidad para replantear su vida, partiendo de afrontar los diferentes sentimientos cuando se les confirma el diagnóstico por primera vez.

En general, las personas en momentos de enfermedad, presentan un mayor apego a lo religioso y espiritual. Esto como consecuencia de la pérdida del control sobre diversas situaciones, que lleva a la búsqueda de las causas de la patología, y que impulsa al individuo a buscar curas sobrenaturales o a poner la solución en manos de un poder más elevado, a través de ello se logra enfrentar algunas situaciones difíciles, estresantes o que conllevan gran ansiedad (22). Estos medios pueden ayudar a hacer frente a la imprevisibilidad, dolor e ira que pueden estar asociados a tener VIH/SIDA $(23,24)$.

En este punto es importante mencionar que la espiritualidad se convierte en un factor importante en sus vidas, generando un significado o propósito, llevando a un confort en su marco de creencias $(25,26)$, al mismo tiempo está asociada con una percepción de mejoría en la vida, y de sensación de bienestar (27, 28). La versión moderna de espiritualidad implica ir más allá del concepto de la religión tradicional, no depende de ella y es utilizada en el acompañamiento de la enfermedad para llegar a un equilibrio entre la salud mental y física (12).

No obstante, algunos investigadores plantean que existen elementos de la religión y los sistemas de valores que representan, por ejemplo, el VIH visto como un castigo de Dios, que pueden exacerbar los sentimientos de culpabilidad y otras emociones negativas en lugar de facilitar la convivencia con el VIH $(29,30)$. Este estado se produce al establecer algunos conceptos de la enfermedad, como su concepción, ya que se considera como la consecuencia de comportamientos desordenados o de la violación de las normas impuestas socialmente. Son entonces posibles intervenciones para mejorar este escenario; la educación al paciente, informarle adecuadamente su diagnóstico, señalarle las opciones de tratamiento y comunicarle el pronóstico (31).

El problema de estigmatización, y rechazo no está en el individuo, sino en las ideas preconcebidas que han quedado fijas en la sociedad a pesar de casi tres decenios de adelantos e información acerca del VIH. Desde el punto de vista de la psicología en el manejo de patologías crónicas, la religión y la espiritualidad se unen para dar una perspectiva de intervención positiva junto con la promoción y prevención (32).

Estudios realizados en países europeos, en especial el Reino Unido, revelan que personas inmigrantes de África que tienen creencias autóctonas, cuando adoptan afiliaciones religiosas propias del país donde residen, desarrollan diferentes efectos positivos; encuentran diversos mecanismos de supervivencia y las nuevas creencias les proporcionan una sensación de fuerza interior para poder hacer frente al VIH (33). También se pudieron observar otros tipos de enfoques utilizados en los pacientes con diagnóstico de $\mathrm{VIH}$, uno de ellos fue la realización de un mantra. Las personas que entonan el mantra, al compararlas con un grupo de control, mostraron una mejoría significativa, hubo reducción en rasgos de ira e incremento $y$ profundidad en la fe espiritual y disminuyeron los niveles de estrés psicológico (34). Este fenómeno ha sido igualmente observado en los familiares de los pacientes, los que alrededor de un $75 \%$ referencian a Dios como una gran fuente de apoyo emocional (35).

\section{Visión del panorama actual}

Las diferencias o semejanzas entre la religión tradicional y la espiritualidad están fundamentadas en el establecimiento de un diálogo interno, en la construcción de un "régimen de vida" como un contexto para la oración; ambas interrumpen pensamientos negativos, promueven el pensamiento positivo, y forjan la obtención de resultados en la salud $(36,37)$.

Sin embargo, en la actualidad algunas religiones interpretan la pandemia por VIH como un castigo de Dios, al pensar que deriva de transgresiones a nivel sexual, que es surgida de un acto inmoral o que ocurre por comportarse de manera contraria a las normas religiosas (38). Por lo anterior, podemos suponer el porqué, algunos líderes religiosos no están haciendo adecuados esfuerzos para combatir la pandemia social de VIH/SIDA y muchas acciones han sido malinterpretadas, aumentado el estigma y la discriminación contra los Pacientes que Viven con el Virus del VIH/ SIDA (PVVS) (39).

Es por esto por lo que la epidemia de $\mathrm{VIH}$ ha revelado múltiples debilidades en el sector salud de nuestras 
sociedades. Por un lado, se presenta una brecha entre estratos sociales que genera restricciones para la accesibilidad de los servicios de salud básicos, forjando un colapso en los sistemas de atención (40). Por otro lado, hay un estado de vulnerabilidad de la mujer para resistir a la infección, un ejemplo son los países africanos en donde las mujeres no pueden ejercer sus derechos sexuales y reproductivos; como la libre elección de reproducción y la posibilidad de exigir relaciones sexuales seguras.

El largo silencio de las instituciones religiosas, gobiernos y de la sociedad en general para hacer frente a los problemas de la sexualidad y a los aspectos preventivos fundamentales ante el VIH/SIDA. A pesar del sinnúmero de declaraciones sobre el potencial de la colaboración y de las tentativas de resolver diferencias ideológicas, los programas exitosos sobre el VIH en los que participan grupos religiosos y laicos son más bien la excepción y no la regla (41). Al hacer un recorrido por las diferentes posturas religiosas que se profesan en el mundo, existen situaciones tanto políticas como de credo que obstaculizan la visión integral del VIH.

A continuación se realizará un recorrido por las principales religiones y se describirá su posición ante la infección por VIH, para comprender el panorama mundial en este contexto:

En el Hinduismo no existe una forma de identificar un dirigente único que pueda representar a la gran variedad de expresiones religiosas que allí se presentan, lo que ha dificultado la generación de proyectos de atención de la enfermedad y la movilización de una acción religiosa a nivel nacional o incluso regional, que facilite la presencia de estructuras formales que sirvan de base para la colaboración y la ejecución de los mismos. Lo anterior está directamente relacionado con el hecho de que en el hinduismo no se exhorta mediante ningún mandamiento a sus practicantes a que den apoyo a aquellos que lo necesitan. Sin embargo, el VIH cambia los comportamientos y actitudes de las comunidades con el tiempo y con la expansión de la epidemia haciendo que se susciten esfuerzos para movilizar a todos los sectores de la sociedad en pro de la creación de programas de prevención, atención y tratamiento, así como de una respuesta religiosa por parte de los líderes hindúes. Esta religión comprende una gran pluralidad de experiencias religiosas, filosóficas y culturales y jerárquicas (llamadas castas) que pueden conducir a hacer distinciones e incluso a restringir el contacto con aquellos que sufren, por motivos de pureza, por lo cual muchas veces se niegan a reconocer problemas sociales como el VIH $(42,43)$.

La Iglesia Ortodoxa tiene un sentido tradicional de la familia y de los valores sociales, basado en la noción del valor de la persona humana y del objetivo final al que esta ideal al que está convocada la humanidad $(44,45)$. La limitación en un manejo conjunto con organizaciones de salud para la prevención y manejo del VIH, está dado al querer incorporar en esta iglesia conceptos de abordaje que puedan causar una falsa imagen de querer establecer a la fuerza normas que estén fuera de las nociones tradicionales, lo que se puede generar por indiferencia de personas ajenas a esta religión hacia los valores y las realidades culturales ortodoxas (41).

En el protestantismo, existen varias respuestas al $\mathrm{VIH} / \mathrm{SIDA}$, no olvidemos que esta religión enmarca una gran variedad de creencias, (desde una visión conservadora y literal de la Biblia hasta un fundamentalismo que cuestiona algunas las enseñanzas de la fe). Entre sus múltiples aproximaciones al respecto, está considerar la enfermedad como una condena y un castigo de Dios a los pecadores, también el realizar complejos análisis sociales, pero finalmente consideran la sexualidad sujeta exclusivamente al matrimonio y a la procreación. Existen grandes diferencias en cuanto a la comprensión del tema, sin embargo, existe una preocupación por la ayuda a los demás y su bienestar en temas de salud, el VIH se ha convertido en el estigma moderno como lo era la lepra en su momento. Esto hace que los creyentes y practicantes de diversas religiones, como la protestante, tengan resistencia y desidia para trabajar por el asunto (46).

Desde el Catolicismo, el enfoque para la enfermedad por VIH/SIDA es el de "castigo divino", como un signo relacionado con un supuesto desenfreno sexual (47). Smedes (48) considera que actualmente hay muchos cristianos que sienten que su sexualidad es el más fuerte competidor para su lealtad a Cristo, llegando a creer que un cristiano no puede amar a Dios y el sexo al mismo tiempo. Sin embargo, lo que constituye el impulso que motiva la respuesta cristiana contemporánea al impacto del VIH y el SIDA en los individuos y las comunidades, es la exhortación de Jesús a mostrar compasión hacia todos los que sufren y son rechazados, a través del mandamiento "Amarás a tu 
prójimo como a ti mismo" (Mateo 22:39), de profesar milagros de curación narrados en la Biblia y también de sus enseñanzas. Lo anterior hace que muchos cristianos presten cuidado y atención especiales a los pobres y marginados de la sociedad (a partir de una serie de valores como son la justicia, la compasión, la solidaridad y la dignidad humana) $(41,49)$.

Es importante mencionar dentro de este contexto que muchas iglesias del cristianismo contribuyen de manera directa con la perpetuación del estigma de las personas que viven con $\mathrm{VIH}$, al no ser incluirlos o negarse a circunscribir iniciativas de promoción al interior de sus comunidades; como ejemplo los programas de prevención del VIH que promueven el uso del preservativo. El Papa Benedicto XVI ha mencionado "la fidelidad en el matrimonio y la salvaguarda que la castidad brinda, siempre debe ser presentada a los creyentes, especialmente los jóvenes, la vida en África, está amenazada por el divorcio, el aborto, la prostitución, el tráfico de personas y una mentalidad anticonceptiva, todo lo cual contribuye al derrumbe de la moral sexual" (50). Esta es la posición de la máxima autoridad de la iglesia católica con respecto al uso del preservativo en el continente africano, en donde hay más casos de la enfermedad, la cual fue criticada por todos los sectores de salud que promocionan su uso para detener la transmisión del virus. Lo que fundamenta como protección la Iglesia Católica es la promoción de la abstinencia sexual fuera del matrimonio y la fidelidad mutua en el matrimonio durante toda la vida, pero para algunos entornos se considera que esta estrategia es muy simplista como una solución para problemas de salud sexual en la población (51). Más aún, cuando estudios adelantados dentro de los lineamientos de la Organización Mundial de la Salud (OMS) identificaron que el tener múltiples parejas sexuales es muy común entre los asistentes a las Iglesias, también evidenció que muchos de los jóvenes miembros de la iglesia, son igual de activos sexualmente y tienen semejantes comportamientos sexuales de riesgo como los que no van a la iglesia (41).

Cambiando de orientación religiosa, algunos estudios cualitativos se han adentrado en las subculturas africanas, encontrando que algunas secciones de las iglesias evangélicas, en Mthatha, Pietermaritzburg, Bulawayo, y Ouagadougou, tienen una enseñanza basada en comentarios negativos, poco compasivos y llenos de culpa con un énfasis primordial en juzgar (52). Los jóvenes de estas comunidades, expresaron una necesidad emocional de recibir ayuda para lidiar con temas de intimidad sexual. Respecto a este tema, hay una total carencia por parte de sus comunidades religiosas, teniendo implicaciones graves en el contexto del VIH y SIDA. Lo anterior conlleva a que se incremente aún más la prevalencia, con el desconocimiento de la relación entre los géneros y la infección en un contexto social en el que la expresión de la masculinidad es implícita a la violencia sexual, también los diferentes tipos de presión social como convivir con el VIH y morir de SIDA.

Desde una perspectiva budista (53), el VIH no representa un hecho inusual, ya que según su doctrina, en el mundo en el que vivimos siempre ha habido enfermedad, sufrimiento, pecado y estigma. No se encontraron dificultades para realizar programas, ya que los monjes budistas siempre tienen una adecuada disponibilidad para el manejo del bienestar de la salud, porque de hecho son compasivos con todo ser humano como parte de sus cánones fundamentales.

La respuesta islámica al VIH es muy variada, por un lado de manera positiva, esta religión brinda a todas las personas dignidad y cortesía en un sentido muy elevado $(54,55)$. En contraposición, la ley consta de medidas de castigo para los actos ilícitos como es el contexto de las relaciones sexuales con comportamientos de riesgo (debido a que se interpreta muchas veces la enfermedad como resultado de una conducta desordenada o de la violación de normas sociales). La transición de la epidemia en el mundo, ha hecho que los islámicos hagan su propia interpretación del comportamiento y tomen medidas de prevención, imprimiéndole un carácter moralista y de identidad que hace ahondar aún más el problema del estigma y la discriminación.

Además, en el ámbito musulmán hay una negación acerca de programas de prevención y tratamiento, básicamente dados por la fusión entre religión y gobierno en la mayoría de los países y la ausencia o debilidad de las prácticas democráticas (56). Dentro de las dificultades para desarrollar programas está el rechazo a admitir que los musulmanes sí están afectados por el VIH/ SIDA y que son afectados como otras comunidades. Una segunda barrera es la creencia de que el comportamiento moral recto de los musulmanes es la única respuesta a este problema (57).

En el Judaísmo, la mitzvah (mandato) de eliminar cualquier obstáculo que pueda representar un peligro para 
la vida sugiere que la medicina preventiva es obligatoria, se puede entonces interpretar como una autorización para lanzar campañas educativas a fin de informar a la gente acerca del VIH y del SIDA, o para usar un preservativo a fin de evitar ser infectado o infectar a otro (58). La respuesta judía al VIH se basa en un sentido de la responsabilidad que obliga a los judíos a atender a todas las personas, judías y no judías, que sufren. Al igual que en otros grupos religiosos, el uso del preservativo es un tema controvertido. El judaísmo tiene una variedad de respuestas respecto a la homosexualidad, las interpretaciones ortodoxas de la ley judía la prohíben, diferente de la postura de las ramas reformistas y reconstruccionistas (41). En las escuelas judías ortodoxas, en Israel o en la diáspora, no se imparte ninguna enseñanza sobre el $\mathrm{VIH}$, sin embargo, algunos educadores consideran que la educación para la prevención del VIH es lícita y han elaborado materiales didácticos para adolescentes $y$ adultos solteros.

\section{Aportes desarrollados}

A partir de las posiciones frente al VIH/SIDA de las religiones mencionadas, que muchas veces se han basado en la vía de transmisión del virus del VIH (sexual o sanguínea en pacientes consumidores de drogas psicoactivas), podemos inferir: en primer lugar, se ha tomado como base la aparente transgresión de la cotidianidad en el comportamiento sexual que refuerza el estigma de la enfermedad, lo que exige una coyuntura por el cambio y la evolución del mundo y también una necesidad de hacer frente a los diversos problemas. En segundo lugar, se han hecho visibles las acciones positivas frente al VIH que llevan a cabo los centros religiosos alrededor del mundo, como son los servicios sobre el $\mathrm{VIH}$ e iniciativas educativas en asocio con gobiernos, organizaciones no gubernamentales, otras comunidades religiosas, y con la sociedad civil (41).

En el Vaticano se están llevando a cabo una reflexión más amplia sobre los métodos de prevención del VIH (59). Entre otros, el Consejo Mundial de Iglesias en 1986 recomendó trabajar en tres puntos de acción: la asistencia pastoral, el ministerio social y la educación/ prevención, además de combatir la discriminación y opresión surgidas por el estigma del SIDA, asegurando la protección de los derechos humanos de las personas afectadas por el virus (60).

La Conferencia Episcopal Católica Sudafricana generó directrices que rigen los métodos de enseñanza para las escuelas católicas, las cuales se mencionan a continuación (61):

1. Hacer frente a la crisis constituyendo un Comité de Asistencia Pastoral que elabore una política general de asistencia pastoral y programas escolares.

2. Integrar un enfoque de la crisis del VIH/SIDA compatible con las enseñanzas de la Iglesia Católica para las escuelas públicas y a estudiantes y profesores de las instituciones de enseñanza y de formación de nivel superior.

3. Las escuelas católicas deben aplicar un programa global de educación sobre el VIH/SIDA en todos los niveles y cursos.

4. Debe prestarse especial atención a los imperativos de una cultura de respeto de la dignidad de la persona humana, que es un don de Dios, y a la comprensión de que la unión sexual es la expresión de una relación humana de amor que ha llegado al estadio de un compromiso mutuo para toda la vida en el seno del matrimonio.

5. Los códigos de conducta adoptados para los educandos y para el personal docente y no docente, deben incluir disposiciones relativas a la inaceptabilidad de comportamientos discriminatorios con respecto a las personas infectadas por el VIH/ SIDA, o bien que puedan ocasionar un riesgo de contagio del VIH.

6. Los programas educativos en materia de $\mathrm{VIH} /$ SIDA y de sexualidad deben incluir la promoción de normas sociales contra las drogas y los abusos sexuales, el comportamiento sexual irresponsable y la violencia sexual.

7. Todos los educadores encargados del cumplimiento de los programas educativos deben recibir una formación adecuada sobre educación en materia de VIH/SIDA y de sexualidad.

Para Noviembre de 2001, la Consulta Mundial sobre las Respuestas Ecuménicas a los Retos del VIH/SIDA en África, en el marco del Consejo Mundial de Iglesias realizaron un plan de acción en la lucha del VIH, el cual consistía en (62): 
1. Instaurar sistemas de información para que se propague a través de las iglesias.

2. Enseñar que el estigma y la discriminación son pecados y cobijar aquellos que son portadores del virus.

3. Asumir papel educativo en materia de sexo y de sexualidad, rompiendo el silencio creado por el malestar y por la tradición.

4. Promover la revisión o la creación de nuevos programas de estudios para los institutos teológicos o seminarios, a fin de que apoyen los objetivos de este plan.

5. Elaborar programas educativos acerca de los diversos modos de transmisión del VIH, destinados a los miembros de las congregaciones, las organizaciones vinculadas a las iglesias, las personas que viven con $\mathrm{VIH} / \mathrm{SIDA}$, los trabajadores del sector de la salud, las ONG's y otros interesados directos.

6. Propiciar y desarrollar la capacidad de las iglesias, para efectuar investigaciones especializadas sobre aquellos aspectos de la pandemia a los que pueden aportar una contribución particular.

En Kenya, el St. Paul's United Theological College logró la acreditación de un programa de Máster en la atención pastoral y el asesoramiento sobre el VIH/ SIDA, este colegio ha estado en la delantera en este tipo de enseñanza (63). Para el año 2003 el encuentro de Primados de la comunidad anglicana estableció que se comprometían de manera más profunda con la educación de los feligreses para protegerse de la transmisión del virus del VIH (64). Grupos como los de Nangurai y Mombo en África, proponen llegar a las comunidades sobre la base de un "liderazgo con propósito", desde la espiritualidad a través de la cual se crea un significado y se recrea una comprensión del mundo (65).

En el año 2004, se dio un ejemplo de vital importancia dado por la Iglesia Católica en la India, donde sus obispos han desarrollado una campaña para proveer información disponible sobre preservativos, sin que ello implique promover, ni propagar su uso (66).

En Bélgica, para el mismo año el Cardenal Godfried Danneels, planteo en una emisión televisiva, la posi- ción de la Iglesia acerca de la abstinencia para prevenir la transmisión del virus, pero expone que si fuesen a ocurrir relaciones sexuales con riesgo, se debería usar el preservativo. Refiriéndose a que moralmente en pacientes con VIH, no era lo mismo que cuando se usaba para no tener hijos. Con una igual posición el Obispo Kevin Dowling de Rustenburg, Sud África, refirió que la abstinencia y la fidelidad son claves para prevenir la transmisión. Sin embargo en el mundo real se deben ofrecer opciones, una de ellas es el uso de preservativos con fines diferentes a la contracepción, con esto se evitan infecciones mortales. Estas declaraciones desempeñan un papel similar al de la encíclica papal en 1968, cuando acepto el uso de anticonceptivos orales en el manejo de hemorragias uterinas. Lo cual ha recibido apoyo por integrantes del Clero, uno de ellos el Cardenal Cormac MurphyO'Connor de Westminster (66).

La Agencia Católica para el Desarrollo en el Extranjero (ACDE), suministra una estrategia de prevención comprehensiva y compasiva, en donde a pesar de la posición política y moral no se puede suprimir información acerca de la disminución del riesgo de transmisión de $\mathrm{VIH}$ al usar los preservativos (66).

Algunas congregaciones en Mozambique tienen más actividades en prevención que las iglesias y son más tolerantes ideológicamente; como resultado, las principales iglesias son más consistentes, directas y constantes en los mensajes de prevención del SIDA, incluso si los líderes no comparten el uso de condones y sexo seguro, si hay muchos más espacios de discusión (67).

Ejemplos como los de las iglesias cristianas, definen en este contexto, que el ser un miembro de la religión implica resolver las contradicciones, redefiniendo las tradiciones religiosas y participando en una amplia labor ideológica revisionista a fin de permitir una interacción entre la religión y su identidad (68).

La V Conferencia de los Obispos Católicos de toda América Latina y el Caribe (69), ha fomentado a una pastoral con personas que viven con el VIH/SIDA de tal manera que efectúe una difusión de información, promoviendo la educación y la prevención, con criterios éticos para contener esta pandemia. Igualmente, se comprometió a asumir un papel de pastores, en donde las personas no sigan llevando el cargo de sentirse castigados por Dios u objetos de juicios moralizantes. 
Para el 2008, líderes religiosos declararon en la conferencia sobre religión y VIH (70), la necesidad de incluir información adecuada sobre el VIH, promoviendo la realización de tamizajes de detección del virus y ofreciendo servicios de prevención del VIH, tratamiento, atención y apoyo.

\section{Conclusiones}

La literatura nos muestra que las creencias religiosas pueden hacer parte de las estrategias para reducir el estigma y la discriminación frente al VIH/SIDA (71). Pero la gran limitación en las personas que conviven con el virus de inmunodeficiencia humana, es que se pueden sentir ajenos a las instituciones religiosas, debido a que existen muchas limitaciones con respecto al abordaje a las personas afectadas, además que en algunas ocasiones son inflexibles con los estilos de vida que llevan los pacientes o incluso con el conocimiento mismo de la enfermedad.

Ante todas estas restricciones por parte de las organizaciones religiosas, se han desarrollado estudios en poblaciones (72) encontrando que la mayoría de los pacientes entrevistados pertenecían a alguna religión, pero el desarrollo de actividades espirituales estaban más enfocadas hacia la oración, y la meditación, lo cual nos puede demostrar que los grupos religiosos no han sido de apoyo de las personas con VIH/SIDA y por lo tanto los pacientes pueden haberse sentido no deseados o condenados a la indiferencia, al considerarlos "no gratos" o "peligrosos" para el bien común en sus propias comunidades de fe. Esta situación puede afectar en gran medida el proceso emocional del paciente, incluso cuando se ha identificado la importancia de la religión en el afrontamiento del diagnóstico del $\mathrm{VIH}$, en el cual distinguimos a la oración como una herramienta narrativa, y los lugares de culto como una fuente de apoyo social para muchas personas con $\mathrm{VIH}$, representando recursos importantes $(73,74)$.

En América Latina, se han generado políticas, programas a nivel de algunas comunidades cristianas que abordan la humanización de la enfermedad. Sin embargo, es una realidad que los actores intervencionistas como son: activistas, médicos y líderes religiosos trabajan de manera aislada (75).

La relación entre la religión y el VIH/SIDA ha estado planteada desde la evolución misma de la enfermedad, las personas que son miembros de las iglesias y las religiones han sido quienes se han aproximaron al dolor de las víctimas. Sin embargo, hablamos de una enfermedad que tiene abundantes franjas morales y tabúes construidos desde la sociedad, por ser de transmisión sexual y porque en sus inicios fue categorizada como una enfermedad exclusiva de hombres que se relacionan sexualmente con otros hombres; esta categorización de la enfermedad es causa de discriminación por parte de aquellos que no comprenden la dinámica del VIH social; por consiguiente, las diferentes religiones seguirán enfocando sus esfuerzos al cuidado de pacientes sin ahondar en un tema fundamental del ser humano: la construcción de la sexualidad.

De ahí la importancia en el empoderamiento de las personas para decidir con plena información, pues ello hace parte de la solución en temas de desarrollo de salud sexual, sin la imposición de principios morales que puedan limitar al individuo en el acceso a tecnologías que protejan su salud (76). Por tanto, las diferentes religiones deben propender por promover cambios personales y sociales que minimicen los riesgos de adquirir el virus, siendo imperativo la construcción de una ética, cuyo punto de partida no sea ni la enfermedad ni la trasgresión. Crear un ambiente de inclusión, dentro del marco de los Derechos Sexuales y Reproductivos, en donde los individuos se sientan parte de la comunidad, sin importar su orientación sexual, condición de salud, económica o cultural (77). Para crear este objetivo, es primordial dentro del entendimiento de la enfermedad, tener un adecuado concepto acerca de la sexualidad humana, donde se identifiquen los mitos y tradiciones nocivas para la integridad del afectado, y se creen caminos de comunicación con la iglesia en todo el mundo $(78,79)$.

\section{Referencias bibliográficas}

1. Royce RA, Seña A, Cates WJJ, Cohen MS. Sexual transmission of HIV. N Engl J Med. 1997; 336(15): 1072-8.

2. Taylor B. HIV, stigma and health: Integration of theoretical concepts and the lived experiences of individuals. Journal of Advanced Nursing. 2001; 35: 792-798.

3. Bueno A, Madrigal A, Mestre F. El SIDA como enfermedad social. Cuadernos de Trabajo Social. 2005; 18 :33-55.

4. Nanda S, Pramanok A. HIV/AIDS in India: stigmatization as a process of communication and social relationship. Cuadernos de Información. Pontificia Universidad Católica de Chile. 2009; 25: 105-117.

5. Encuesta Nacional de Demografía y Salud. Profamilia. Ministerio de Protección Social. Republica de Colombia. 2010. 
6. Simbaqueba V., Pantoja C., Torres B, Ávila C. Voces Positivas, Resultados del Índice de Estriga en personas que viven con $\mathrm{VIH}$ en Colombia. Red Colombiana de Personas que Viven con VIH RECOLVIH 2011.

7. Quiceno J, Vinaccia S. La salud en el marco de la psicología de la religión y la espiritualidad. Diversitas Perspectivas en psicología. 2009; 5(2): 321- 336.

8. Maristany C. El poder Terapéutico de la Escucha en Medicina Crítica. HUMANITAS, Humanidades Médicas. 2008; 27.

9. Hill PC, Pargament KI. Advances in the conceptualization and measurement of religion and spirituality. Implications for physical and mental health research. Am Psychol. 2003; 58: 64-74

10. Guillory JA, Sowell R, Moneyham L, et al. An exploration of the meaning and use of spirituality among women with HIV/ AIDS. Altern Ther. 1997; 3: 102-108.

11. Dunbar HT, Mueller C, Medina C, et al. Psychological and spiritual growth in women living with HIV. Social Work. 1998; 43: 144-154.

12. Koenig, HG. Concerns about Measuring "Spirituality" in Research. The Journal of Nervous and Mental Disease, 2008; 196(5): 349-355.

13. Green, E. C. Faith-based organizations: Contributions to HIV prevention. The Synergy Project. United States Agency for International Development. 2003.

14. Kilbourne AM, Justice AC, Rollman BL, et al. Clinical importance of HIV and depressive symptoms among veterans with HIV infection. J Gen Intern Med. 2002; 17: 512-20.

15. Santana M, Dancy B. The stigma of being named "AIDS carriers" on Haitian-American women. Health Care Women Int. 2000; 21(3): 161-71.

16. Ironson G, Solomon G, Balbin EG, et al. The Ironson-Woods Spirituality/Religiousness Index is associated with long survival, health behaviors, less distress, and low cortisol in people with HIV/AIDS. Ann Behav Med. 2002; 24: 34-48.

17. Yi M, Mrus J. Religion, Spirituality, and Depressive Symptoms in Patients with HIV/AIDS. J Gen Intern Med. 2006; 21: 21-27.

18. Simoni JM, Ortiz MZ. Mediational models of spirituality and depressive symptomatology among HIV-positive Puerto Rican women. Culture Divers Ethnic Minor Psychol. 2003; 9: 3-15.

19. Ickovics JR, Hamburger ME, Vlahov D, et al. Mortality, CD4 cell count decline, and depressive symptoms among HIV-seropositive women: longitudinal analysis from the HIV Epidemiology Research Study. JAMA. 2001; 285: 1466-74.

20. Atkinson JH, Grant I. Natural history of neuropsychiatric manifestations of HIV disease; Psychiatr Clin North Am. 1994; 17: 17-33.

21. Siegel K, Schrimshaw EW. The perceived benefits of religious and spiritual coping among older adults living with HIV/AIDS. Journal for the Scientific Study of Religion. 2002; 41: 91-102.

22. Koenig HG, George, LK, Siegler IC. The use of religion and other emotion-regulating coping strategies among older adults. The Gerentolosist. 1998; 28: 303-310.

23. Prado G, Feaster DJ, Schwartz SJ, Pratt IA, Smith L, Szapocznik J. Religious involvement, coping, social support, and psychological distress in HIV-seropositive African American mothers. AIDS Behav. 2004; 8: 221-35.

24. Kaldjian LC, Jekel JF. Friedland G. End-of-life decisions in HIV-positive patients: the role of spiritual beliefs. AIDS 1998; 12: 103-107.

25. Lorenz K, Hays R, Shapiro M, Cleary P, Asch S, Wenger N. Religiousness and spirituality among HIV-infected Americans. J Pall Med. 2005; 8: 774-81.
26. Prisla Ücker P, Campio M, Tiellet M. Psicologia em Estudo, Maringá. 2008; 13(3): 523-530.

27. Tuck I, McCain NL, Elswick RK Jr. Spirituality and psicosocial factors in persons living with HIV. J Adv Nurs. 2001; 33: 776-83.

28. Zilber C. Psychotherapeutic strategies for coping with HIV infection. What Mental Health Practitioners Need to Know About HIV and AIDS. San Francisco, Jossey-Bass. 2000; 37-44.

29. Somlai AM, Heckman TG, Kelly JA, Mulry GW, Multhauf $\mathrm{KE}$. The response of religious congregations to the spiritual needs of people living with HIV/AIDS. J Pastoral Care. 1997; 51: 415-26.

30. Kiw E. Religion as a community resource for wellbeing: prevention, healing, and empowerment pathways. J Soc Issues. 1995; 51: 177-93.

31. Mc Enany G, Hughes A, Lee K. Depresión y HIV Una Perspectiva de Intervención sobre una Compleja Relación. RET, Revista de Toxicomanías. 1998; 15.

32. Yoffe L. Efectos positivos de la religión y la espiritualidad en el afrontamiento de duelos. Psicodebate, 2007; 7: 193-205.

33. Anderson J, Doyal L. Women from Africa living with HIV in London: a descriptive study. AIDS Care. 2004; 16: 95-105

34. Bormann J, Gifford A, Shively M. Effects of spiritual mantram repetition on hiv outcomes: a randomized controlled trial. Journal of Behavioral Medicine, 2006; 29(4): 359-376.

35. Castellanos C. Atención Domiciliaria: Detección temprana de los síntomas de Burn Out en familiares que cuidan a personas con VIH/SIDA. Ciencia y Sociedad. 2009; 34(1): 120-132.

36. Heelas P. The New Age Movement. Oxford: Blackwell Publishers.1996.

37. Cotton S, Puchalski C. Spirituality and religion in patients with HIV/AIDS. J Gen Intern Med. 2006; 21: 5-13.

38. Okunna C, Dunu I. Religious constraints on reporting HIV/ AIDS in Nigeria (Paper presented at the conference on "Religion, Media and Health in West Africa with a focus HIV \& AIDS" 13-15 December 2006 Accra Ghana).

39. Oluduro $O$. The role of religious leaders in curbing the spread of HIV/AIDS in Nigeria, Per/Pelj. 2010; 13(3): 208-232.

40. Manoj K. Una perspectiva Cristiana. Perspectivas, 2002; 32(2): 1-13.

41. Lux S, Greenaway K. Ampliar las alianzas efectivas: Una guía para trabajar con las organizaciones religiosas en la respuesta al VIH y el SIDA. Publicada conjuntamente por la Alianza Ecuménica de Acción Mundial, Ayuda de la Iglesia Noruega, la Conferencia Mundial de las Religiones por la Paz, Church World Service y ONUSIDA. Primera edición. Noruega. Copyright 2006.

42. Aram K Grillo J. The Human Dimension: Voices from the Hindu World. Interreligious dialogue. World Conference of Religion and Peace Publisher Shanti Ashram 2010: 3-12.

43. Sen A. The Argumentative Indian. Penguin Books. 2005.

44. Huston S. Las religiones del mundo. Barcelona: Kairós. 2002.

45. Sullivan L. Las características del prostestantismo. Italia. Editorial Nerea S.A. 2008.

46. Torres L, Serrano I. Las iglesias protestantes en Puerto Rico ante el VIH/SIDA: Opiniones de líderes de dos denominaciones. R. Interam Psicol. 2007; 41(2): 167-176

47. Viteri M. Discursos sobre el VIH/SIDA: Un estudio en parejas heterosexuales viviendo con VIH/SIDA [Tesis de maestría en ciencias sociales con especialización en estudios de genero]. Quito: Facultad Latinoamericana de Ciencias Sociales. Sede Flacso; 2003.

48. Smedes L. Sex for Christians: The limits and liberties of sexual living. Library of Congress Cataloling Ed. Edermanns Publising co. 1994: 27-60. 
49. La Sagrada Biblia. King James version. Grand Rapids (MI): Zondervan Publishing House; 1995. Mateo 22:39.

50. Discurso del Papa Benedicto XVI a los Obispos de Sudáfrica, Botsuana, Suazolandia, Namibia, y Lesotho en visita "AD LIMINA". Ciudad del Vaticano. Editorial Editrice Vaticana. 2005.

51. Booth K. Local women, global science: Fighting AIDS in Kenya. Bloomington: Indiana University Press. 2004.

52. Marshall M, Taylor N. Cómo afrontar el VIH y SIDA con comunidades con base en la fe: aprendiendo de las actitudes hacia las relaciones entre los géneros y los derechos sexuales dentro de las iglesias evangélicas en Burkina Faso, Zimbabwe y Sudáfrica. Gender \& Development. 2006; 14(3): 1-11.

53. Mae Chan, Chiang Rai. Sermons based on Buddhist Precepts: A response to HIV/AIDS. South East Asia HIV and Development Project. December 2000. Disponible en: http://www. ahrn.net/library_upload/uploadfile/th0013.pdf

54. Positive muslims. HIV, AIDS \& Islam, Reflections based on Compassion. Responsibility \& Justice. Published by Positive Muslims. Cape Town, South Africa 2004.

55. Kelley L, Eberstadt N. Behind the Veil of a Public Health Crisis: HIV in the Muslim World. NBR special report. Publisher The national bureau of Asian research. 2005

56. Kelly L, Eberstadt N. El VIH/SIDA en el Mundo Islámico. Desidamos. Revista de la Fundación para Estudio e Investigación de la Mujer. 2005; 13(1): 20-21.

57. Musso S, Fanget F, Cherabi K. La religión y la educación para la prevención del VIH/SIDA: una perspectiva árabe-musulmana. Perspectivas. UNESCO. 2002;21(2): 114-122.

58. Steinitz L. The AIDS Pandemic: Jewish Values and Responsibilities. Journal of Jewish Communal Service. Otoño-invierno. $2005 ; 115-120$.

59. Vitillo, R.A Faith-Based Response to HIV in Southern Africa: the Choose to Care Initiative. UNAIDS best practice collection. 2006: 17-20.

60. Actas de la 38 ${ }^{a}$ reunión del Comité Central del Consejo Mundial de Iglesias. AIDS and the Church as a healing community. WCC Executive Committee statement 1987; 6:135.

61. Catholic Institute of Education Southern African Catholic Bishops. Conference Policy on HIV/AIDS for Catholic schools. January 2000. QNGS Disponible en: http://www.cso.za.org/ HIV_AIDS_SACBC_policy_Catholic_Schools_2000.pdf

62. The Ecumenical Response to HIV/AIDS in Africa (EHAIA). Plan of Action, Global Consultation on Ecumenical Responses to the Challenges of HIV/AIDS in Africa. Nairobi, Kenya, 25-28 November 2001.

63. Mwangi M. Community transformation: A case study of St Paul's life long learning (SPILL), Master of Arts/post graduate diploma in community care and HIV \& AIDS programme. Mainstreaming HIV and AIDS in theological education: experiences and explorations. Switzerland, World Council of Churches. WCC Publications. 2008: 19-32.

64. Primados Anglicanos, Informe de la reunión de Primados de la Comunión Anglicana. Apéndice III: Declaración de los Primados Anglicanos sobre el VIH/SIDA. Canterbury (Reino Unido), 17 de abril de 2002.
65. Dantley M. Critical spirituality: Enhancing transformative leadership through critical theory and African American prophetic spirituality. International Journal of Leadership in Education. 2003; 6(1): 3-17.

66. Informe de Católicas por el Derecho a Decidir. Premios a Obispos Católicos. Desidamos. Revista de la Fundación para Estudio e Investigación de la Mujer. 2005; 13 (1). 21-26.

67. Agadjanian V. Gender, religious involvement, and HIV/AIDS prevention in Mozambique. Social Science \& Medicine. 2005; 61: 1529-1539.

68. Leong P. Religion, flesh, and blood" re-creating religious culture in the context of $\mathrm{h}$ iv/aids sociology of religion. 2006; 67(3): 295-311.

69. Regan D. Hna. La Fe, Religión y VIH/SIDA. Ponencia en el I Congreso Internacional de Actualización en VIH SID - Hospital Dr. Mario Catarino Rivas. 2007.

70. ONUSIDA. Guyana National Declaration on Faith and HIV. Conference in Georgetown Guyana. Reference document, December 11th 2008.

71. Zou J, Yamanaka Y, Muze J, Watt M, Ostermann J, Thielman N. Religion and HIV in Tanzania: influence of religious beliefs on HIV stigma, disclosure, and treatment attitudes. BMC Public Health. 2009; 9: 75.

72. Coleman C. The contribution of religious and existential wellbeing to depression among African American heterosexuals with HIV infection. Issues Ment Health Nurs. 2004; 25: 103-10.

73. Palma I. Las instituciones religiosas en la transformación normativa contemporánea en la sexualidad en Chile. Revista de Psicología, Universidad de Chile. 2008; 17(2): 9-37.

74. Ridge D, Williams I, Anderson J, Elford J. Like a prayer: the role of spirituality and religion for people living with HIV in the UK. Sociology of Health \& Illness. 2008; 30(3): 413-428.

75. Bastidas F. Abordaje espiritual en el acompañamiento a personas que viven con VIH/Sida: Una perspectiva experiencial desde la fe cristiana. Revista Educación en Valores. Universidad de Carabobo. 2009; 1(11).

76. Sinding S. La estrategia CNN: preservativo, agujas y negociación vs. la ABC: Abstinencia, fidelidad y preservativos. Desidamos. Revista de la Fundación para Estudio e Investigación de la Mujer. 2005; 13(1).

77. Hernandez C. Ética, iglesia y VIH/SIDA: Más allá del terrorismo sexual. Presencia Ecuménica. 2009; 67: 23-27.

78. Consejo Mundial de Iglesias. Crear alianzas entre las iglesias y las organizaciones de personas que viven con el VIH y el SIDA. Conferencia de Iglesias de Toda el África, Pacto sobre el VIH/SIDA, Octava Asamblea General de la Conferencia de Iglesias de Toda el África, Yaoundé (Camerún), 22-27 noviembre 2003. Disponible en http://www.iglesiacatolica. org.gt/vih/svih03.pdf

79. Agrippa K. Teaching and talking about our sexuality: a means of combating HIV/AIDS. HIV/AIDS and the curriculum: methods of integrating HIV/AIDS in theological programmes. Geneva: WCC Publications; 2003. 